\title{
Stakeholder reactions to company crisis communication and causes
}

Lynette M. McDonald, Beverley Sparks, A. Ian Glendon

\section{Abstract}

Despite the burgeoning number of studies examining stakeholder effects of crisis communication and crisis causes, the varied categorizations used, together with inconsistent findings, has meant that knowledge gaps remain. Specifically, existing studies have not established whether a significant hierarchy of best communicated accounts exist that minimize crisis impact on stakeholder reactions. In addition, whether different crisis causes have different emotional, attitudinal and behavioral outcomes still requires examination. Further, crisis emotion research has been limited and has predominantly investigated anger and sympathy, indicating the need to explore a greater variety of crisis emotions. This investigation of the impact of a hierarchy of five crisis communication accounts and four crisis causes on multiple stakeholder reactions elicited several key findings. Although “confession” was the most preferred crisis account, "no comment” was almost as successful in mitigating negative reactions. Counterintuitively, confession reduced responsibility judgments. No comment was second to confession in mitigating negative, and promoting positive, reactions. Further, company control of a crisis was found to be the single most powerful predictor of stakeholder reactions. Involvement elicited multiple positive and negative crisis emotions, while different emotion categories elicited different behavioral intentions. Attitude to the company also impacted behavioral intentions. 
Crises typically involve and affect multiple stakeholders. Consumers sometimes suffer injury or death, investors potentially experience financial losses, the public may be placed at risk, corporate managers lose employment (Siomkos, 1989), and employee jobs are threatened due to the potential for business collapse. Two known determinants of stakeholder crisis reactions are crisis communication and crisis cause or type. Experimental investigation of crisis communication is a rapidly growing research area (Coombs \& Holladay, 2009), and includes accounts that can mitigate or aggravate stakeholder reactions. Accounts address responsibility acceptance for negative events (Weiner, 1995) such as a crisis. Although accounts are one of the few managerial tools available to public relations managers to mitigate negative outcomes during a crisis, little research has successfully investigated the effects of a hierarchy of different crisis accounts on stakeholder reactions. As responses become more accommodating to stakeholders they become more expensive (Stockmyer, 1996). The success of less accommodative accounts would provide practitioners with lower cost communication options.

Substantial crisis cause research exists, including a plethora on crisis typologies (e.g., Coombs \& Holladay, 2002, 2005; Egelhoff \& Sen, 1992; Mitroff \& Pearson, 1993). One method of classifying crises is by stakeholders' perceptions of the underlying crisis cause, that is, by its causal dimensions as advocated by Coombs (1995) using Weiner’s (1986) Attribution Theory (WAT). Yet crisis studies have failed to investigate whether two main causal dimensions of controllability (controllable, uncontrollable) and locus (internal, external) have separate stakeholder outcomes, despite service researchers finding different causal dimension effects.

Emotions facilitate or impede the effectiveness of crisis response strategies (Coombs \& Holladay, 2005) as publics enact strategies to deal with their feelings (Jin, 2009). However, crisis emotions are little researched. There is a strong need to explore a variety of crisis emotions (Choi \& Lin, 2009a), in particular their impact on attitude to the company and upon 
stakeholder behaviors. Stakeholder behavior in response to crises is of great concern to both public relations scholars (Fediuk, Pace, \& Botero, 2010) and crisis managers. Researchers (e.g., McDonald \& Härtel, 2000) have also suggested that stakeholder involvement with a crisis determines crisis outcomes, yet little research has examined its crisis role (Choi \& Lin, 2009b). In addition, crisis research in settings outside North America is rare (Lee, 2004). As managers require theoretically developed and tested knowledge to provide crisis management guidelines (Laufer \& Coombs, 2006), our study adds to existing crisis research by using an experimental survey design to investigate the impact of accounts and crisis causes on multiple stakeholder reactions in an Australian setting.

\section{Literature review and hypotheses}

Much research has identified two major determinants of stakeholders' reactions to company crisis: the company's crisis communication and the crisis cause.

\subsection{Determinants of crisis reactions: organizational accounts}

Following news of a breaking crisis, the media presses the company for a statement. Crisis communication frequently contains a reputation-building account. Accounts are explanations of a serious event designed to minimize its perceived severity and stakeholder antagonism, and reduce damage to the organization's image and reputation (Ginzel, Kramer, \& Sutton, 1992). Managers may strategically select accounts that they believe best suit a particular crisis

situation (Garrett, Bradford, Meyers, \& Becker, 1989). Negative publicity studies (e.g., Fitzpatrick \& Rubon, 1995; Garrett et al., 1989) have identified five accounts commonly used by organizational spokespeople - no comment, denial, excuse, justification and confession. 


\subsubsection{A stakeholder-preferred account hierarchy}

An extensive review located 16 studies (Coombs, 1999; Coombs \& Holladay, 1996, 2008, 2009; Coombs \& Schmidt, 2000; Dean, 2004; Griffin et al., 1991; Jorgensen, 1996; Menon, Jewell, \& Unnnava, 1999; Lee, 2004, 2005; Siomkos, 1989; Siomkos \& Kurzbard, 1994; Siomkos \& Malliaris, 1992; Siomkos \& Shrivastava, 1993; Stockmeyer, 1996) reporting significant crisis communication results. Although denial and no comment generally had negative effects, and confession or its components (e.g., compassion, apology, compensation, super-effort) generally had positive effects, no clear evidence emerged for a stakeholderpreferred account hierarchy. While Bradford and Garrett’s (1995) negative publicity study tested five responses (no response, denial, excuse, justification, concession) in four evidence situations on image, significant results for separate responses were not reported. No study was identified that reported significant results for justification, despite Garrett et al.’s (1989) finding that this was managers' preferred response. Congruent with Fediuk et al.’s (2009) suggestion, research on a crisis account hierarchy is needed.

Viewing accounts as responsibility reduction strategies, Weiner (1995) suggested that highest responsibility acceptance occurs with confession, then justification and excuse, with denial having the lowest responsibility acceptance. No comment avoids addressing responsibility. Congruent with this hierarchy and previous crisis research, we suggest that a responsibilityreducing account hierarchy exists. We predict the most negative stakeholder reactions for no comment, then denial, and excuse, with better results for justification, and best results for confession. The crisis communication studies earlier cited also make evident the research paucity regarding significant account effects on emotions (other than anger, sympathy, or general affect), attitude and behavior. This suggests the following hypothesis: 
Hypothesis 1. Accounts impact stakeholders' judgment of responsibility, emotions, attitude, and behavioral intentions, with worst results for no comment, then denial, and excuse, with better results for justification, and best results for confession.

\subsection{Crisis causes and stakeholder reactions}

Two theories successfully applied to explaining how crisis causes and organizational accounts influence stakeholder reactions are Weiner's $(1986,1995)$ attribution theory (WAT) and Coombs and Holladay’s (2002) Situational Crisis Communication Theory (SCCT), revised by Coombs (2007). Both theories posit that, following a negative event, stakeholders make attributions about its cause along causal dimensions. Causal dimension judgments are formulated from information gleaned from the media, the company, and other sources (Klein \& Dawar, 2004). Research using WAT has identified two reliable causal dimensions: locus (whether the cause was inside or outside the company) and controllability (whether the cause was under company control). Both theories indicate that determining the event cause leads to a responsibility judgment that, in turn, results in emotions, influencing behavior. Weiner (1995) suggested that mitigating circumstances, such as those given in an account, reduce the responsibility judgment. Further, events that are more personally relevant cause stronger emotions (Weiner, 1995). However, McDonald and Härtel (2000) contended that personal relevance was poorly conceptualised and argued instead for the application of involvement to crises. Congruent with this research, we contend that the more involved that stakeholders are with a crisis, the stronger their resulting emotions.

A review of multiple crisis studies indicated nine reporting significant crisis cause effects: Coombs (1998), Coombs and Holladay (2002, 1996), Griffin et al. (1991), Jorgensen (1994, 1996), Kim, Kim, and Cameron (2008), Lee (2005, 2004). Of these, five examined combined crisis causes of locus (internal, external) and controllability (controllable, uncontrollable) 
finding that internal controllable crises resulted in responsibility judgments, anger, and schadenfreude, and negative behavioral intentions. Four of the five studies also examined external uncontrollable crises, finding that this type of crisis had more positive outcomes for attitude and behavior than did internal controllable crises. However, none of these studies examined the separate effects of crisis causes of locus (internal, external) and controllability (controllable, uncontrollable). Folkes’ (1984) service failure investigation found separate causal effects, with locus linked to customers requiring an apology and not being charged, and controllability linked to anger and revenge. Therefore it is expected that crisis locus and controllability may contribute separately to stakeholder crisis reactions. Understanding these separate effects is important because crises may not just have internal and controllable causes (e.g., neglected maintenance) or external and uncontrollable causes (e.g., terrorist sabotage), but also internal yet uncontrollable causes (e.g., employee sabotage), or external and controllable causes (e.g., failure to protect against a common external threat). As controllability is closely related to responsibility (Weiner, 1995), compared to locus it is expected to produce more negative results. Further, we contend that crisis causes directly impact involvement and responsibility, which then impact emotions, with emotions determining attitude and behavior. This leads to the following hypotheses:

Hypothesis 2a. Crisis locus (internal, external) impacts involvement, responsibility, emotions, attitude, and behavior, with worst results for internal crises and better results for external crises.

Hypothesis 2b. Crisis controllability (controllable, uncontrollable) impacts involvement, responsibility, emotions, attitude, and behavior, with worst results for controllable crises and better results for uncontrollable crises.

Hypothesis 2c. Controllability will more strongly impact stakeholder reactions than will locus. 


\subsection{Determinants of stakeholder emotions: involvement, responsibility}

Research using WAT and SCCT has found that crisis responsibility predicted negative emotions (Choi \& Lin, 2009a; Jorgensen, 1996), positive emotions (Choi \& Lin, 2009a), and was positively correlated with anger and schadenfreude and negatively correlated with sympathy (Coombs \& Holladay, 2005). Therefore, stronger crisis responsibility should predict stronger emotional reactions. Crisis involvement is also key to predicting emotions (McDonald \& Härtel, 2000), with the crisis involvement-anger link supported by Choi and Lin’s (2009b) analysis of the Mattel toy crisis. This leads to the following hypothesis.

Hypothesis 3: The higher the levels of involvement and responsibility, the more intense the resultant positive and negative emotions.

\subsection{Determinants of stakeholder behavior: emotions, attitude}

Several crisis studies using WAT or SCCT found that emotions drive behavioral intentions. Anger predicts punitiveness (Jorgensen, 1996), negative purchase intentions (Coombs \& Holladay, 2007; Jorgensen, 1996), negative word-of-mouth (WOM) behavior (Coombs \& Holladay, 2007), and indirectly reduces investment intentions (Jorgensen, 1996). Sadness results in a preference for emotional support and positive thinking, while fear leads to venting intentions or avoidance (Jin, 2009). Despite the fact that post-crisis stakeholder affect can powerfully motivate stakeholders, the effect of crisis emotions on behavior has been little investigated (Coombs \& Holladay, 2005). Although WAT’s thinking-feeling-acting sequence leads to the expectation that attitude predicts behavior, two crisis studies (Jorgensen, 1996; Lee, 2005) using WAT reported no attitude-behavior path. Despite these findings, congruent with WAT, the following hypothesis is derived. 
Hypothesis 4. Emotions and attitude predict behavioral intentions, with positive emotions and attitude predicting positive behavioral intentions, and negative emotions predicting negative behavioral intentions.

\section{Method}

\subsection{Design and materials}

The study used a 5 (account: no comment, denial, excuse, justification, confession) x 2 (crisis locus: internal, external), x 2 (crisis controllability: controllable, uncontrollable) design examining effects on involvement, responsibility, emotions (anger, fear, joy, surprise, sympathy), attitude, and behavioral intentions (loyalty, negative WOM, complaining). Air crash scenarios, previously successfully used for crisis studies (Jorgensen, 1996; Lee, 2004) were developed. Participants were randomly assigned to one of 20 account/crisis cause combinations. The crisis cause scenarios appeared as front-page newspaper stories with a large crash photo detailing the crash of a small domestic airliner. A separate company account story described the airline’s Chief Executive Officer's response. Appendix 1 lists story headlines. The airline was described as long-established and reputable, with no prior crash history. Participants were asked to imagine that they or loved ones were recent customers of the airline.

\subsection{Preliminary Research}

Several convenience sample pre-tests refined scenarios, checked their believability and realism, and examined question clarity. As emotion scales should be context-specific (Richins, 1997), and because an extensive review indicated no emotion scales well-suited to crises, scales were developed from two pre-tests. An emotion list was generated via focus groups $(n=53)$ using a general population sample, and categorized using Shaver, Schwarz, Kirson, and Connor's (1987) extensive emotion list. Following testing on a student sample $(n=316)$, factor analysis 
indicated emotion scales of anger, fear, surprise, joy and sympathy. This study also tested accounts and crisis cause identification, and examined their manipulation checks.

\subsection{Participants}

A general population sample was randomly selected from a recently updated electoral roll for a major Australian city. With voting compulsory in Australia, 93\% of eligible citizens are listed on this roll (Australian Electoral Commission, 2006-2007), which is the best publicly-available sample source, and the most commonly used source for government population surveys. Of 4500 questionnaires posted, 942 responses were received (907 usable responses, 20.9\% response rate) - within the $20 \%$ to $25 \%$ range typically produced by random samples generated through publicly-available sources (Hunsaker, Cioffi, Amadio, Wright, \& Caughlin, 2002). Respondents were aged between 18 and 95 years $(M=45.7, S D=15.6), 60 \%$ were female. Respondents' demographic profile (age, income, gender, education) closely matched that of government population data, although the 45 to 54 age group was slightly over-represented, males were slightly under-represented, and education levels were slightly higher in our sample.

\subsection{Measures}

All measures used 7-point scales (Not at all, Very much). Pre-tested manipulation checks investigated perceptions of crash cause locus and controllability, account identification, scenario believability, and realism. Kent and Allen’s 3-item scale (1994, in Bruner, James, \& Hensel, 2001) checked account credibility. McQuarrie and Munson’s (1992) scale measured involvement (important/unimportant, matters/doesn't matter, significant/insignificant, of interest/not of interest). Karuza, Zevon, Gleason, Karuza, and Nash’s (1990) 3-item scale measured responsibility, reduced to two items in testing. Scales assessed company-directed emotions of anger (angry, disgusted, annoyed, outraged), joy (satisfied, enjoyment, contented, glad), surprise (surprised, astounded, shocked, amazed), and sympathy (sympathetic, sorry, 
compassion, empathy), and emotions towards flying with the company of joy and fear (apprehensive, scared, distressed, fearful). For attitude, we used Milliman, Fugate, and Afzalurrahim’s (1991, in Bruner \& Hensel, 1998) scale. Behavioral intention items from scales by Zeithaml, Berry, and Parasuraman (1996) and Singh (1988, in Bruner et al., 2001) measured negative word-of-mouth intentions (NWOM), complaining and loyalty. Exploratory and confirmatory factor analysis increased scale reliability and validity.

\section{Results}

\subsection{Scale reliabilities and manipulation checks}

Cronbach’s alpha indicated good reliability of scales for involvement, responsibility, anger, joy, surprise, sympathy, fear; attitude to the company, NWOM, complaining, and loyalty ( $\alpha=$ $.91, .78, .89, .83, .86, .85, .93, .93, .94, .89, .85$ respectively). Both crisis locus ( $M_{\text {internal }}=2.53$ vs $\left.M_{\text {external }}=3.99\right)$ and controllability $\left(M_{\text {controllable }}=2.83\right.$ vs $\left.M_{\text {uncontrollable }}=3.99\right)$ were perceived as intended, as were accounts $(F, 20,3404=97.82, p<.001)$. Although excuse was not significantly different from denial or justification, results were in expected directions. Posthoc tests indicated significant differences between account credibility perceptions $(F(4,867)=$ 38.91, $p<.001)$, with confession $(M=4.92)$ being most credible, then no comment $(M=3.82)$, excuse $(M=3.50)$, denial $(M=3.06)$, and justification $(M=2.92)$.

\subsection{Hypotheses results}

MANOVAs indicated main effects for accounts and crisis causes. A Bonferroni adjustment ( $p$ $<$.025) revealed significant differences between response variables (see Table 1).

Table 1 here 


\subsubsection{Account}

Hypothesis 1's contention that account would impact responsibility, emotions, attitude, and behavior was mostly supported (see Table 2). Account had a significant main effect ( $F$ (40, $3000=2.94, p<.001$, Pillai's trace $=.15$, partial $\eta^{2}=.04$ ) on responsibility, anger, sympathy, attitude, NWOM, and loyalty. The predicted account hierarchy was not evident (see Table 2), although denial, excuse and justification resulted in significantly higher anger and lower sympathy, loyalty, and attitude than did confession. No comment significantly lowered responsibility compared to excuse.

Table 2 here

\subsubsection{Crisis causes}

Hypothesis 2a's contention for crisis locus that internal crises would have more negative effects and external crises more positive effects was supported, with effects for almost all variables (see Table 1 and Appendix 2). Locus had a significant main effect $(F(11,721)=7.62$, $p<.001$, Pillai's trace $=.29$, partial $\eta^{2}=.10$ ). In the internal (vs external) crisis, participants judged the company as significantly more responsible, and were more angry, fearful, surprised, felt less joy, had a poorer company attitude, more NWOM, and less loyalty. Hypothesis 2b’s contention for crisis controllability that controllable crises would have more negative effects and uncontrollable crises more positive effects was supported, with effects for almost all variables (see Table 1 and Appendix 2). Controllability had a significant main effect ( $F(11$, $721)=10.66, p<.001$, Pillai's trace $=.14$, partial $\eta^{2}=.14$ ). In the controllable crisis (vs uncontrollable), participants judged the company as significantly more responsible, and were more angry, fearful, had less joy and sympathy, had a poorer attitude, less loyalty, were more likely to complain, and expressed more NWOM. Hypothesis 2c's contention that, compared to 
locus, controllability would more strongly impact crisis reactions was supported, as indicated by examining the $F$-test and partial eta squared effect size in Table 1.

\subsubsection{Emotion predictors}

Hypothesis 3's contention that involvement and responsibility would impact all emotions was supported in five regression analyses (see Figure 1). Responsibility and involvement predicted $38.5 \%$ of anger's variance $(F(2,843)=265.91, p<.001) ; 23.8 \%$ of fear's variance $(F(2,846)$ $=133.40, p<.001) ; 15.7 \%$ of joy's variance $(F(2,832)=78.38, p<.001) ; 13.5 \%$ of sympathy's variance $(F(2,831)=65.90, p<.001)$; and $8.60 \%$ of surprise's variance $(F(2,832)$ $=40.43, p<.001)$. Compared to involvement, responsibility more strongly impacted emotions, being especially powerful for anger, fear, and sympathy.

\subsubsection{Behavior predictors}

Hypothesis 4's contention that emotions and attitude would impact NWOM, loyalty, and complaining was mostly supported in three regression analyses (see Figure 2). Attitude, fear, anger, and joy predicted $61.1 \%$ of NWOM's variance $(F(6,836)=221.60, p<.001)$. Attitude, fear, and joy predicted 55\% of loyalty's variance $(F(6,836)=169.14, p<.001)$. Anger and fear predicted $30.2 \%$ of complaining's variance $(F(6,836)=61.69, p<.001)$. The strongest predictors for NWOM, loyalty and complaining were, respectively, fear, attitude, and anger.

\section{Discussion and implications}

While confirming the general thrust of research using SCCT and WAT, this study elicited several key findings of value to scholars and practitioners. First, confession was the preferred company account, no matter what the crisis cause, best at mitigating anger and NWOM, and increasing sympathy, loyalty, and attitude. Although confession accepts crisis responsibility, it had the second lowest responsibility rating, in contrast to previous research findings. Use of 
denial, excuse, or justification, which all seek to reduce responsibility judgments, instead increased these judgments and, in doing so, attracted strong negative stakeholder reactions. This lends credence to practitioners' calls for confession's wider use to limit crisis reputation damage when legal responsibility and stakeholder recompense is inevitable. Second, despite negative effects for silence or no comment in studies by Menon et al. (1999) and Griffin et al. (1991), “no comment” was second only to confession for significantly mitigating anger and NWOM, and increasing sympathy, loyalty and positive attitude. Further, no comment received the lowest responsibility judgment. The positive reactions to confession and no comment may be related to their credibility, earlier reported. It may indicate that, in a crisis, it may be best to either say nothing or else "fess up", as the three other accounts consistently produced negative reactions.

However, as this study found that crisis causes were far more powerful in determining stakeholder reactions compared to organizational accounts, crisis communication may not be particularly effective in either combating negative or promoting positive stakeholder reactions.

Third, this study examined the separate effects of controllability and locus finding that crisis controllability is the single strongest predictor of anger, sympathy, and negative attitude. As stakeholders depend on media-filtered information to determine crisis cause, when the crisis is not fully under organisational control, the media relations strategy should be to impart this information to mitigate negative reactions. For both crisis causes, companies can expect impacts on responsibility, anger, joy, attitude, NWOM, and loyalty. However, each cause had some unique effects for locus and controllability. When the crisis originated inside the company, stakeholders were more fearful and surprised. This may reflect expectations of high company standards regarding safety. However, as fear leads to NWOM, for crises with an internal cause, practitioners need to be vigilant in monitoring weblogs and social media in 
order to combat NWOM. For crises with causes that are not company-controllable, practitioners may expect sympathetic stakeholders, while in controllable crises, expect complaints directed at the company, media and authorities.

Fourth, as predicted, stakeholder crisis involvement influenced all emotions. This may have resulted from requesting participants to imagine close links with the crisis. However, compared to responsibility, involvement plays a lesser role in explaining emotional response, with responsibility being especially powerful in predicting anger, fear, and sympathy. As Coombs and Holladay (2005) indicated, crisis responsibility is pivotal to predicting emotions and future organizational interactions.

Fifth, this study provided evidence that different emotion categories drive different behavioral intentions: fearful and angry stakeholders indulge in NWOM, angry stakeholders are driven to complain, and those reporting joy (e.g., in an external or uncontrollable crisis) are more loyal.

Finally, although previous crisis studies (e.g., Jorgensen, 1996; Lee, 2004) failed to find a significant path between attitude and behavioral intentions, we found that negative attitude impacted NWOM, which prior studies had indicated can damage company reputation. Yet, for crises resulting in a more positive attitude (those caused by factors beyond the company's control) this positive attitude was loyalty’s strongest predictor - having even stronger effects than did emotions. In a crisis where maintaining stakeholder loyalty and reducing NWOM is paramount, measuring attitude may provide a shorthand predictor of likely crisis outcome.

\section{Limitations and further research}

A study using created scenarios compromises realism. Its static format may not fully reflect the dynamic processes operating during a crisis, limiting its generalizability. In reality, a company 
may change accounts over time, and stakeholders’ perceptions of crisis causes may be revised as new evidence emerges (e.g., in media stories). Field studies to examine stakeholders’ reactions to a breaking crisis would contribute much research value and could derive more applications-based outcomes. Further testing of the positive effects of no comment and the confession-responsibility link also seem warranted.

\section{References}

Australian Electoral Commission (2008). Australian Electoral Commission annual report 2006-2007 - An effective electoral roll. Retrieved from http:// www.aec.gov.au/?About_AEC/Publications/Annual_Reports/2007/outcome1.htm

Bradford, J. L., \& Garrett, D. E. (1995). The effectiveness of corporate communicative responses to accusations of unethical behavior. Journal of Business Ethics, 14, 875892.

Bruner II, G. C., \& Hensel, P. J. (1998). Marketing scales handbook: A compilation of multi-item measures (Vol. II). Chicago: American Marketing Association.

Bruner II, G. C., James, K. E., \& Hensel, P. J. (2001). Marketing scales handbook: A compilation of multi-item measures (Vol. III). Chicago: American Marketing Association.

Choi, Y., \& Lin, Y. (2009a). Consumer responses to Mattel product recalls posted online bulletin boards: Exploring two types of emotion. Journal of Public Relations Research, 21, 198-207.

Choi, Y., \& Lin, Y. (2009b). Consumer response to crisis: Exploring the concept of involvement in Mattel product recalls. Public Relations Review, 35, 18-22.

Coombs, W. T. (2007). Protecting organization reputation during a crisis: The development and application of Situational Crisis Communication Theory. Corporate Reputation Review, 10, 163-176. 
Coombs, W. T. (1999). Information and compassion in crisis responses: A test of their effects. Journal of Public Relations Research, 11, 125-142.

Coombs, W. T. (1998). An analytic framework for crisis situations: Better responses from a better understanding of the situation. Journal of Public Relations Research, 10, 177-191.

Coombs, W. T. (1995). Choosing the right words: The development of guidelines for the selection of the "appropriate" crisis-response strategies. Management Communication Quarterly, 8, 447-476.

Coombs, W. T., \& Holladay, S. J. (2009). Further explorations of post-crisis communication: Effects of media and response strategies on perceptions and intentions. Public Relations Review, 35, 1-6.

Coombs, W. T., \& Holladay, S. J. (2008). Comparing apology to equivalent crisis response strategies: Clarifying apology's role and value in crisis communication. Public Relations Review, 34, 252-257.

Coombs, W. T., \& Holladay, S. J. (2007). The negative communication dynamic: Exploring the impact of stakeholder affect on behavioral intentions. Journal of Communication Management, 11, 300-312.

Coombs, W. T., \& Holladay, S. J. (2005). An exploratory study of stakeholder emotions: Affect and crises. In N. Ashkanasy, W. J. Zerbe, \& C. E. J. Härtel (Eds.), The effect of affect in organizational settings: Research on emotion in organizations (pp. 263-280). New York: Elsevier.

Coombs, W. T., \& Holladay, S. J. (2002). Helping crisis managers protect reputational assets. Management Communication Quarterly, 16, 165-186.

Coombs, W. T., \& Holladay, S. J. (1996). Communication and attributions in a crisis: An experimental study of crisis communication. Journal of Public Relations Research, 8, 279-295. 
Coombs, W. T., \& Schmidt, L. (2000). An empirical analysis of image restoration: Texaco’s racism crisis. Journal of Public Relations Research, 12, 163-178.

Dean, D. H. (2004). Consumer reaction to negative publicity: Effects of corporate reputation, response, and responsibility for a crisis event. Journal of Business Communication, 41, 192-211.

Egelhoff, W. G., \& Sen, F. (1992). An information-processing model of crisis management. Management Communication Quarterly, 5, 443-484.

Fediuk, T. A., Pace, K. M., \& Botero, I. C. (2010). Crisis response effectiveness: Methodological considerations for advancement in empirical investigation into response impact. In W. T. Coombs \& S. J. Holladay (Eds.), Handbook of crisis communication (pp. 221-242). Malden, MA: Wiley-Blackwell.

Fitzpatrick, K. R., \& Rubon, M. S. (1995). Public relations vs legal strategies in organizational crisis decisions. Public Relations Review, 21, 21-34.

Folkes, V. (1984). Consumer reactions to product failure: An attributional approach. Journal of Consumer Research, 10, 398-409.

Garrett, D. E, Bradford, J. L., Meyers, R. A., \& Becker, J. (1989). Issues management and organizational accounts: An analysis of corporate responses to accusations of unethical business practices. Journal of Business Ethics, 8, 507-520.

Ginzel, L. E., Kramer, R. M., \& Sutton, R. I. (1992). Organizational impression management as reciprocal influence process: The neglected role of the organizational audience. Research in Organizational Behavior, 15, 227-266.

Griffin, M., Babin, B. J., \& Attaway, J. S. (1991). An empirical investigation of the impact of negative public publicity on consumer attitudes and intentions. Advances in Consumer Research, 18, 334-341. 
Hunsaker, F., Cioffi, D., Amadio, P., Wright, J., \& Caughlin, B. (2002). The American College of Orthopaedic Surgeons outcomes instruments: Normative values from the general population. Journal of Bone and Joint Surgery, 84, 208-215.

Jin, Y. (2009). The effects of public's cognitive appraisal of emotions in crises on crisis coping and strategy assessment. Public Relations Review, 35, 310-313.

Jorgensen, B. (1996). Components of consumer reaction to company-related mishaps: A structural equation model. Advances in Consumer Research, 23, 346-351.

Jorgensen, B. (1994). Consumer reaction to company-related disasters: The effect of multiple versus single explanations. Advances in Consumer Research, 21, 348-352.

Karuza, J., Zevon, M. A., Gleason, T. A., Karuza, C. M., \& Nash, L. (1990). Models of helping and coping, responsibility attributions, and wellbeing in community elderly and their helpers. Psychology and Aging, 5, 194-208.

Kim, J., Kim, H. J., \& Cameron, G. T. (2008). Are your corporate crisis responses effective? The effects of crisis types and corporate responses on the public's perceptions of organizational responsibility for crisis. Proceedings of the $11^{\text {th }}$ International Public Relations Research Conference, Holiday Inn, University of Miami, Florida.

Klein, J., \& Dawar, N. (2004). Corporate social responsibility and consumers’ attributions and brand evaluations in a product-harm crisis. International Journal of Research in Marketing, 21, 203-217.

Laufer, D., \& Coombs, W. T. (2006). How should a company respond to a product harm crisis? The role of corporate reputation and consumer-based cues. Business Horizons, 49, 379-385.

Lee, B. K. (2005). Hong Kong consumers' evaluation in an airline crash: A path model analysis. Journal of Public Relations Research, 17, 363-391. 
Lee, B. K. (2004). Audience-oriented approach to crisis communication: A study of Hong Kong consumers’ evaluation of an organizational crisis. Communication Research, 31, 600-618.

McDonald, L., \& Härtel, C. E. J. (2000). Applying the involvement construct to organisational crises. Proceedings of the Australian and New Zealand Marketing Academy Conference, Gold Coast, Australia.

McQuarrie, E. F., \& Munson, J. M. (1992). A revised product involvement inventory: Improved usability and validity. Advances in Consumer Research, 16, 697-702.

Menon, G., Jewell, R. D., \& Unnava, H. R. (1999). When a company does not respond to negative publicity: Cognitive elaboration vs negative affect perspective. Advances in Consumer Research, 26, 325-329.

Mitroff, I. I., \& Pearson, C. M. (1993). Crisis management: A diagnostic guide for improving your organization’s crisis-preparedness. San Francisco: Jossey-Bass.

Richins, M. L. (1997). Measuring emotions in the consumption experience. Journal of Consumer Research, 24, 127-146.

Shaver, P., Schwartz, J., Kirson, D., \& O’Connor, C. (1987). Emotion knowledge: Further exploration of a prototype approach. Journal of Personality and Social Psychology, 52, 1061-1086.

Siomkos, G. J. (1989). Managing product-harm crises. Industrial Crisis Quarterly, 3, $41-60$.

Siomkos, G. J., \& Kurzbard, G. (1994). The hidden crisis in product-harm crisis management. European Journal of Marketing, 28, 30-41.

Siomkos, G. J., \& Malliaris, P. G. (1992). Consumer response to company communications during a product harm crisis. Journal of Applied Business Research, 8, 59-65. 
Siomkos, G. J., \& Shrivastava, P. (1993). Responding to product liability crises. Long Range Planning, 26, 72-79.

Stockmyer, J. (1996). Brands in crisis: Consumer help for deserving victims. Advances in Consumer Research, 13, 429-435.

Weiner, B. (1995). Judgments of responsibility. New York: Guilford.

Weiner, B. (1986). An attributional theory of motivation and emotion. New York: Springer.

Appendix 1

Crisis causes and accounts operationalized

Crisis causes News story headline

Internal and controllable Airline’s neglected engine maintenance caused crash

Internal and uncontrollable Airline maintenance crew sabotage caused crash

External and controllable $\quad$ Bird strike caused crash - safety device not yet installed

External and uncontrollable Terrorist sabotage caused crash despite high security

Accounts News story headline

No comment

CEO refuses to comment on crash

Denial

CEO denies responsibility for crash

Excuse

CEO shifts crash responsibility

Justification

CEO downplays crash severity

Confession

CEO apologizes and takes full responsibility for crash 
Appendix 2

Variables with significant differences for Locus and Controllability Crisis

\begin{tabular}{lllll}
\hline & \multicolumn{3}{c}{ Locus Crisis } & \multicolumn{2}{l}{ Controllability Crisis } \\
\cline { 2 - 5 } Predictor & Internal & External & Controllable & Uncontrollable \\
variables & $M$ & $M$ & $M$ & $M$ \\
Responsibility & 5.57 & 4.76 & 5.58 & 4.75 \\
Anger & 4.75 & 4.12 & 4.87 & 4.03 \\
Fear & 5.05 & 4.58 & - & - \\
Surprise & 4.43 & 4.05 & - & - \\
Joy & 2.08 & 2.39 & 2.08 & 2.38 \\
Sympathy & - & - & 2.85 & 3.54 \\
Attitude & 2.80 & 3.18 & 2.63 & 3.34 \\
NWOM & 4.47 & 3.75 & 4.49 & 3.73 \\
Loyalty & 2.01 & 2.42 & 2.05 & 2.39 \\
Complain & - & - & 3.01 & 2.50 \\
\hline
\end{tabular}


Table 1

Main effects for account and crisis cause

\begin{tabular}{|c|c|c|c|c|c|c|c|c|c|}
\hline & Account & & & Locus & & & Contrc & y Crisis & \\
\hline Variable & $F$ & $p$ & Partial $\eta^{2}$ & $F$ & $p$ & Partial $\eta^{2}$ & $F$ & $p$ & Partial $\eta^{2}$ \\
\hline Responsibility & 5.22 & $<.001$ & .03 & 64.17 & $<.001$ & .08 & 66.37 & $<.001$ & .08 \\
\hline Anger & 12.41 & $<.001$ & .06 & 24.24 & $<.001$ & .03 & 48.82 & $<.001$ & .06 \\
\hline Fear & - & - & - & 14.60 & $<.001$ & .02 & - & - & - \\
\hline Surprise & - & - & - & 8.42 & .004 & .01 & - & - & - \\
\hline Joy & _ & _ & _ & 11.53 & .001 & .02 & 11.14 & .001 & .02 \\
\hline Sympathy & 8.65 & $<.001$ & .04 & _ & _ & _ & 38.82 & $<.001$ & .05 \\
\hline Attitude & 12.39 & $<.001$ & .06 & 12.95 & $<.001$ & .02 & 46.45 & $<.001$ & .06 \\
\hline Complain & - & - & - & - & - & - & 18.29 & $<.001$ & .02 \\
\hline Loyalty & 5.52 & $<.001$ & .03 & 22.77 & $<.001$ & .03 & 15.92 & $<.001$ & .02 \\
\hline NWOM & 4.38 & .002 & .02 & 23.54 & $<.001$ & .03 & 25.55 & $<.001$ & .03 \\
\hline
\end{tabular}


Table 2

Impact of account on response variables

\begin{tabular}{|c|c|c|c|c|c|c|c|c|c|c|c|c|c|}
\hline & \multicolumn{8}{|c|}{ Account } & & & \multicolumn{3}{|c|}{ ANOVA results } \\
\hline & \multicolumn{2}{|c|}{ No Comment } & \multicolumn{2}{|c|}{ Denial } & \multicolumn{2}{|c|}{ Excuse } & \multicolumn{2}{|c|}{ Justification } & \multicolumn{2}{|c|}{ Confession } & & & \\
\hline & \multicolumn{2}{|c|}{$n=174$} & \multicolumn{2}{|c|}{$n=171$} & \multicolumn{2}{|c|}{$n=173$} & \multicolumn{2}{|c|}{$n=172$} & \multicolumn{2}{|c|}{$n=183$} & & & \\
\hline & $M$ & $S D$ & $M$ & $S D$ & $M$ & $S D$ & $M$ & $S D$ & $M$ & $S D$ & $F$ & $\eta^{2}$ & $p$ \\
\hline Responsibility & $4.88^{\mathrm{e}}$ & 1.60 & 5.06 & 1.58 & $5.41^{\mathrm{f}}$ & 1.47 & 5.25 & 1.44 & 4.95 & 1.58 & 3.54 & .02 & .007 \\
\hline Anger & $4.09^{c}$ & 1.81 & $4.64^{\mathrm{b}}$ & 1.79 & $4.65^{b d}$ & 1.75 & $4.75^{b d}$ & 1.64 & $3.76^{\mathrm{a}}$ & 1.73 & 10.74 & .05 & $<.001$ \\
\hline Sympathy & 3.36 & 1.59 & $3.06^{b}$ & 1.62 & $2.91^{\mathrm{b}}$ & 1.55 & $3.03^{b}$ & 1.45 & $3.76^{\mathrm{a}}$ & 1.57 & 8.55 & .04 & $<.001$ \\
\hline NWOM & $3.72^{b}$ & 2.13 & 4.26 & 2.00 & $4.36^{\mathrm{a}}$ & 2.12 & 4.26 & 2.15 & $3.69^{b}$ & 2.09 & 4.08 & .02 & .003 \\
\hline Loyalty & 2.37 & 1.23 & $2.14^{\mathrm{b}}$ & 1.22 & $2.15^{b}$ & 1.16 & $2.06^{b}$ & 1.15 & $2.57^{\mathrm{a}}$ & 1.28 & 5.34 & .02 & $<.001$ \\
\hline Attitude & $3.08^{b}$ & 1.59 & $2.81^{b}$ & 1.58 & $2.77^{b}$ & 1.50 & $2.82^{b}$ & 1.37 & $3.64^{\mathrm{a}}$ & 1.55 & 10.23 & .05 & $<.001$ \\
\hline
\end{tabular}




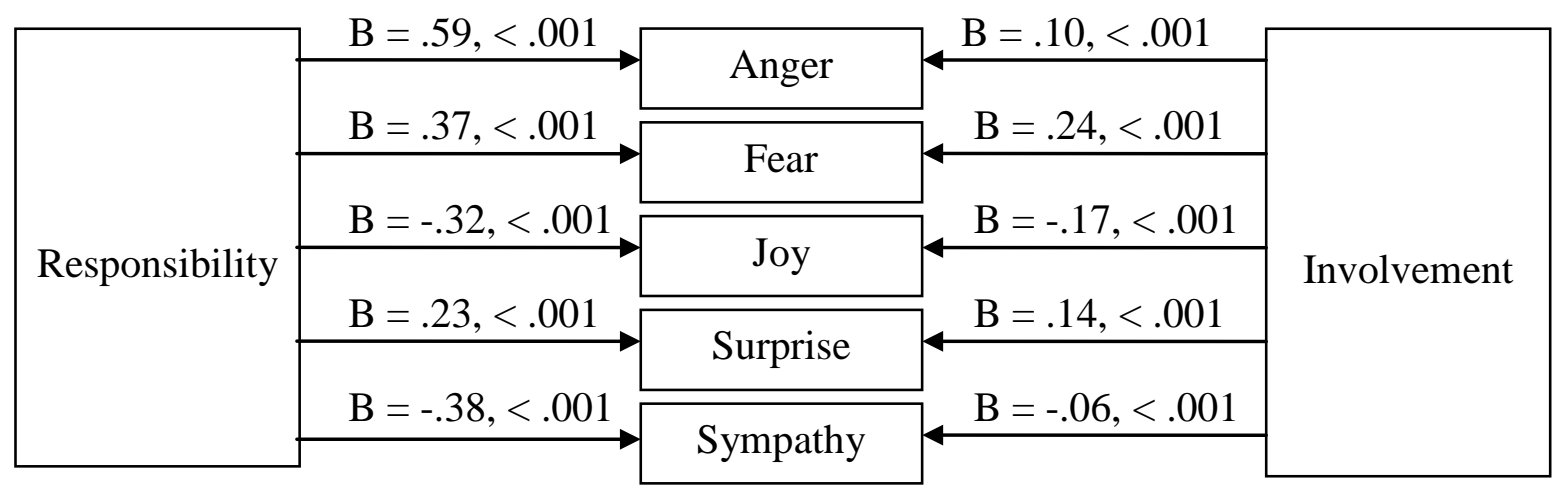

Directional arrows show $\beta$ values; all $p$ values $<.001$

Figure 1. Impact of responsibility and involvement on emotions

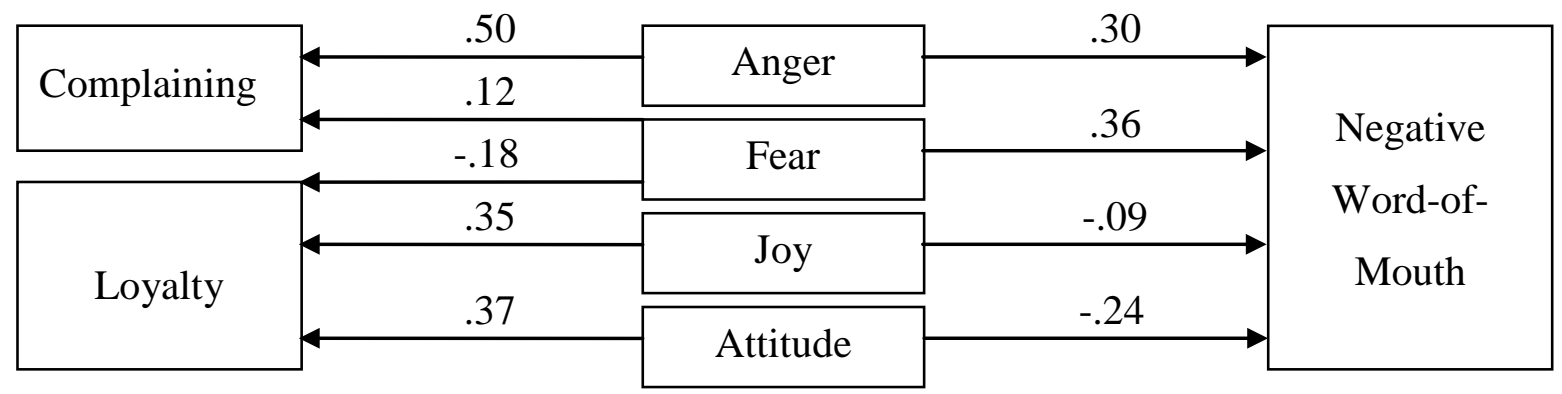

Directional arrows show $\beta$ values; all $p$ values $<.001$

Figure 2. Impact of emotions and attitudes on behavioral intentions 